\title{
Emergency corneal grafting in the UK: a 6-year analysis of the UK Transplant Registry
}

\author{
Parwez Hossain, ${ }^{1,2}$ Abdo Karim Tourkmani, ${ }^{2}$ Dimitri Kazakos, ${ }^{1}$ Mark Jones, ${ }^{3}$ \\ David Anderson, ${ }^{2}$ on behalf of the NHS Blood and Transplant Ocular Tissue Advisory \\ Group and Contributing Ophthalmologists
}

\begin{abstract}
${ }^{1}$ Academic Unit of Clinical Experimental Sciences, Faculty of Medicine, University of Southampton, Southampton General Hospital, Southampton, UK

${ }^{2}$ Southampton Eye Unit, Southampton General Hospital, Southampton, UK

${ }^{3}$ Statistics and Audit Directorate, NHS Blood and Transplant, Bristol, UK
\end{abstract}

\section{Correspondence to} Dr Parwez Hossain, Eye Unit, MP104, University of Southampton, Southampton General Hospital, Tremona Road, Southampton S016 6YD, UK: parwez@soton.ac.uk

Received 15 November 2016 Revised 19 April 2017 Accepted 23 April 2017 Published Online First 11 May 2017

\section{CrossMark}

To cite: Hossain $\mathrm{P}$, Tourkmani AK, Kazakos D, et al. Br I Ophthalmol 2018:102:26-30.

\begin{abstract}
Background Corneal graft (CG) surgery is the most common and successful tissue transplant worldwide. A small and important group of patients are operated in emergency situations, typically to save a perforated eye. Our knowledge of the indications and outcomes of emergency corneal graft (eCG) is limited.

Methods Retrospective, multifactorial analysis of all CGs registered by the UK Transplant Service from April 1999 to March 2005.

Results A total of 12976 CGs were performed. 1330 (11.4\%) were eCGs including 433 regrafts. Actual perforation occurred in $876(65.9 \%)$ patients. 420 $(31.5 \%)$ grafts were for tectonic purposes alone and 217 $(16.3 \%)$ were also grafted for visual rehabilitation. The main diagnostic categories were infection (39.4\%), noninfectious ulcerative keratitis (32.2\%) and other causes (ectasias, previous ocular surgery, injury, dystrophies and opacification). Graft survival of first eCG at 1,2 and 5 years was $78 \%, 66 \%$ and $47 \%$, respectively. Best-corrected visual acuity of surviving grafts at 1 year was: $6 / 12$ or better in $29.9 \%, 6 / 18$ to $6 / 60$ in $38.4 \%$, counting finger to LP in $30.6 \%$ and NPL in $1 \%$, with worsening of vision in only $8.7 \%$ of the patients. Conclusion This study which is the largest of its kind shows that despite the seriousness of the critical corneal pathology and the surgical challenges that it poses, the outcomes of eCG are favourable with most patients keeping their eyesight and avoiding immediate rejection. These clinical outcomes show the value of eye banking facilities that are developed to support corneal tissue supply for eCG.
\end{abstract}

\section{INTRODUCTION}

Corneal allografting is the oldest, most common and successful tissue transplantation procedure worldwide. ${ }^{1-4}$ The majority of corneal grafting (CGs) are performed under elective conditions, however, a smaller and more critical group of patients are operated in emergency situations. In such cases, emergency corneal graft (eCG) surgery is often the only solution to stabilise the globe and retain ocular integrity in patients with severe corneal disorders or persistent infectious and non-infectious keratitis. Failure to act urgently would likely lead to severe visual loss or loss of the eye. ${ }^{5}$

Emergency keratoplasty is regarded as high-risk surgery in comparison to elective keratoplasty, with worse outcomes and higher postoperative complication rates; however, the evidence on the indications, risk factors for graft failure and outcomes of eCG is patchy. There are studies from USA, ${ }^{6}$ Australia, New Zealand, ${ }^{8}$ UK, ${ }^{9-11}$ Germany, ${ }^{12}$ France, ${ }^{13}$ Italy ${ }^{14}$ Sweden, ${ }^{15}$ Israel,,${ }^{16}$ Turkey, ${ }^{17}$ Saudi Arabia, ${ }^{18}$ Taiwan, ${ }^{19}$ China, ${ }^{20}$ India,${ }^{21}$ Canada,${ }^{22}$ Hungary, ${ }^{23}$ $\operatorname{Iran}^{24}$ and Singapore ${ }^{25}$ that have either concentrated on a subtype of eCG or have small number of eCGs, usually grouped under 'other' indications. We present a retrospective study with the largest cohort of eCG patients by using the UK Transplant Registry, a database with over 30000 patients. The data provide the indications, graft survival and outcomes of this procedure. Such knowledge would benefit patient counselling, clinical management and planning of eye bank services for eCG.

\section{MATERIALS AND METHODS Data collection}

We analysed data from all eCGs from April 1999 to March 2005 that were registered with UK Transplant Service, the UK's matching and distribution service. eCGs are classified by using 'reasons for grafts': therapeutic (severe infection, threatened or actual perforation) as selected by the surgeons on the UK Ocular Tissue Transplant Record form.

Records were submitted by the operating surgeon or doctors involved in the patients' care at the day of the operation (routine CG registration) and at intervals of 1,2 and 5 years thereafter until graft failure, loss to follow-up or death of the patient has occurred. Missing data were routinely sought by follow-up letter. Ethical approval was not required as the data are being routinely collected for such purposes.

We analysed information on the graft procedure, indication for surgery, demographics, vision before and after surgery, rejection episodes and graft failure. Additional data include host and surgical factors that could affect outcome such as: the presence of tissue inflammation, infection, ocular surface disease, extent of vascularisation, glaucoma and other coexisting disease. Surgical factors analysed include suturing technique, graft-host trephine sizes and the development of postoperative complications as indicated in the UK transplant audit follow-up forms.

\section{Statistical analyses}

All statistical analyses were performed using SAS V.9.1. Kaplan-Meier survival curves were used to illustrate univariate differences in graft survival, and a Cox regression model was fitted to investigate 


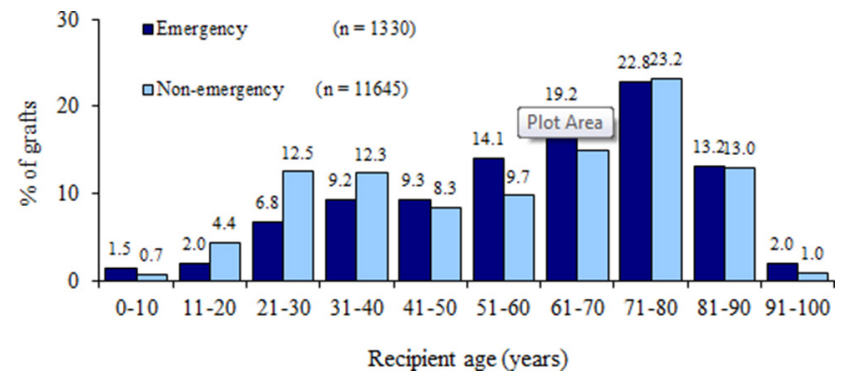

Figure 1 Age distribution of study patients. The emergency graft group was slightly older compared with other recipients, and the difference in age distributions was highly significant $(p<0.0001)$. The median age was 64 years (IQR=47-76) for emergency-grafted recipients compared with 62 years (IQR=37-76) for all other recipients. Other recipients showed an initial peak in the 21-40 year olds, which was mainly due to the large number of patients with keratoconus in these age groups. Approximately $20 \%$ of emergency-grafted recipients were aged 40 or under, compared with $30 \%$ of other recipients.

which factors affected graft survival. $\chi^{2}$ tests were used to investigate differences in categorical variables, and t-tests were used to investigate differences in continuous variables between emergency and all other CGs.

To enable comparison of a homogeneous group, graft survival, rejection and visual acuity were limited to first eCG. Postoperative visual acuity and refractive data were limited to assessments between 8 and 16 months from the day of eCG surgery for 1-year outcomes and between 18 and 30 months for 2-year outcomes.

\section{RESULTS}

A total of 12976 CGs performed between April 1999 and March 2005 have been reported to UK Transplant Service, $11646(88.6 \%)$ of which were done under elective conditions and 1330 (11.4\%) under emergency circumstances. Records were submitted by a total of 498 surgeons from 273 centres, approximately half of which were involved in eCG surgery (244 (48\%) surgeons from 147 (54\%) centres). All operation registration UK Transplant Service forms were returned, whereas the completion rate of follow-up audit forms was $90 \%$ at year $1,85 \%$ at year 2 and $74 \%$ at year 5 . Detailed information on transplants was not available prior to April 1999. The mean age of eCG recipients at the time of transplantation was 60 years (SD 20) compared with 56 (SD 22) for corneal grafts performed under routine conditions and varied from less than 1 year to more than 98 years (figure 1). Approximately equal numbers of women $(51 \%)$ and men $(49 \%)$ had received an eCG. The proportion of eCGs that were human leucocyte antigen (HLA) matched was only $3 \%(44 / 1330)$ compared with $7 \%(823 / 11646)$ for elective CGs. Recipients of 147 grafts (11\%) were known to have died, and 84 grafts $(6 \%)$ had been lost to follow-up. Two patients recorded as lost to follow-up had actually died.

\section{Indications/diagnosis}

These were similar for both first-time eCG (897 patients, 67.4\%) and repeat eCG surgery (433 patients, 32.6\%). The main diagnostic categories for first eCG were infection (353 patients, $39.4 \%$ ), non-infectious ulcerative keratitis (289 patients, 32.2\%) and other including ectasias (7\%), previous ocular surgery $(5.7 \%)$, injury (4.1\%), dystrophies (2.6\%) and opacification $(1.9 \%)$. For repeat eCG, the diagnostic categories were graft failure (230 patients, 53.1\%) infection (84 patients, 19.4\%),
Table 1 Indication for emergency corneal graft (eCG)

\begin{tabular}{|c|c|c|c|c|}
\hline \multirow[b]{2}{*}{ Indication for eCG } & \multicolumn{2}{|l|}{ First graft } & \multicolumn{2}{|l|}{ Regraft } \\
\hline & $\mathrm{n}(\mathrm{S} / \mathrm{T} / \mathrm{A})$ & $\%$ & $n(S / T / A)$ & $\%$ \\
\hline Ectasias & $63(11 / 53 / 19)$ & 7.0 & $4(1 / 2 / 2)$ & 0.9 \\
\hline Keratoconus & $53(11 / 47 / 15)$ & 5.9 & $2(1 / 1 / 1)$ & \\
\hline Keratoglobus & 3 & 0.3 & - & \\
\hline Other ectasias & $7(0 / 6 / 4)$ & 0.8 & $2(0 / 1 / 1)$ & \\
\hline Dystrophies & $23(15 / 12 / 7)$ & 2.6 & $4(0 / 4 / 0)$ & 0.9 \\
\hline Fuchs' dystrophy & $16(12 / 9 / 4)$ & 1.8 & $4(0 / 4 / 0)$ & \\
\hline Other dystrophies & $7(3 / 3 / 3)$ & 0.8 & - & \\
\hline Previous ocular surgery & $51(20 / 27 / 14)$ & 5.7 & $11(2 / 5 / 5)$ & 2.5 \\
\hline $\begin{array}{l}\text { Pseudophakic corneal } \\
\text { oedema }\end{array}$ & $30(13 / 19 / 4)$ & 3.3 & $3(1 / 0 / 0)$ & \\
\hline $\begin{array}{l}\text { Aphakic corneal } \\
\text { oedema }\end{array}$ & $9(5 / 5 / 3)$ & 1.0 & - & \\
\hline $\begin{array}{l}\text { Complications of } \\
\text { refractive surgery }\end{array}$ & 1 & 0.1 & - & \\
\hline $\begin{array}{l}\text { Other previous ocular } \\
\text { surgery }\end{array}$ & $11(2 / 3 / 7)$ & 1.2 & $8(1 / 5 / 4)$ & \\
\hline Infection & $353(150 / 59 / 217)$ & 39.4 & $84(46 / 22 / 44)$ & 19.4 \\
\hline Viral infection & $99(25 / 23 / 67)$ & 11.0 & $18(3 / 6 / 13)$ & 4.2 \\
\hline Bacterial infection & $187(108 / 33 / 139)$ & 20.8 & $52(35 / 12 / 29)$ & 12.0 \\
\hline Fungal infection & $19(17 / 3 / 11)$ & 2.1 & $10(8 / 4 / 2)$ & 2.3 \\
\hline Protozoan infection & $24(19 / 9 / 4)$ & 2.7 & $2(2 / 0 / 1)$ & 0.5 \\
\hline Other infection & $24(14 / 5 / 16)$ & 2.7 & $2(1 / 0 / 1)$ & 0.5 \\
\hline Injury & $37(1 / 9 / 30)$ & 4.1 & $12(1 / 2 / 11)$ & 2.8 \\
\hline Mechanical injury & 17 & 1.9 & 4 & 0.9 \\
\hline Chemical injury & 12 & 1.3 & 6 & 1.4 \\
\hline Other injury & 8 & 0.9 & 2 & 0.5 \\
\hline Ulcerative keratitis & $289(16 / 28 / 262)$ & 32.2 & $61(5 / 9 / 54)$ & 14.1 \\
\hline Rheumatoid arthritis & $134(6 / 9 / 127)$ & 14.9 & $19(1 / 0 / 19)$ & 4.4 \\
\hline $\begin{array}{l}\text { Other ulcerative } \\
\text { keratitis }\end{array}$ & $155(10 / 19 / 135)$ & 17.3 & $42(4 / 9 / 35)$ & 9.7 \\
\hline Graft failure & & & $230(80 / 94 / 119)$ & 53.1 \\
\hline Rejection & & & $32(10 / 21 / 13)$ & 7.4 \\
\hline Primary failure & & & $16(5 / 9 / 3)$ & 3.7 \\
\hline Endothelial failure & & & $8(4 / 4 / 1)$ & 1.8 \\
\hline High astigmatism & & & $1(1 / 1 / 1)$ & 0.2 \\
\hline Endophthalmitis & & & $5(4 / 1 / 3)$ & 1.2 \\
\hline Other cause of failure & & & $168(56 / 58 / 98)$ & 38.8 \\
\hline Opacification & $17(3 / 14 / 4)$ & 1.9 & $3(2 / 3 / 0)$ & 0.7 \\
\hline Other & $56(8 / 15 / 45)$ & 6.2 & $20(4 / 2 / 16)$ & 4.6 \\
\hline Unknown/not reported & $8(2 / 3 / 3)$ & 0.9 & $4(2 / 2 / 2)$ & 0.9 \\
\hline Total & $897(259 / 234 / 621)$ & & $\begin{array}{l}433 \\
(146 / 145 / 255)\end{array}$ & \\
\hline
\end{tabular}

$\mathrm{S} / \mathrm{T} / \mathrm{A}$, severe infection/threatened perforation/actual perforation.

non-infectious ulcerative keratitis (61 patients, $14.1 \%$ ) and other including ectasias (1\%), previous ocular surgery $(2.5 \%)$, injury $(2.8 \%)$, dystrophies (1\%) and opacification $(0.7 \%)$ (table 1).

Overall, severe infection (S), threatened (T) and actual (A) perforation were reported in 405 (30.5\%), $379(28.5 \%)$ and 876 (65.9\%) patients, respectively. Of note, many patients had a combination of pathologies, that is, severe infection with threatened perforation, $84(6.3 \%)$; severe infection with actual perforation, 15 (1.1\%); severe infection with threatened perforation that perforated, $40(3 \%)$; threatened perforation that perforated, 151 (11.4\%). Additionally, some patients were operated with no visual expectation (for cosmetic and tectonic reasons) and only 217 (24.8\%) were having good visual potential. 
The patients' mean age at time of surgery per indication were: 59 (SD, 19) for severe infection, 54 (SD, 24) for threatened perforation and 62 (SD, 19) for actual perforation. There was significant age difference per indication when comparing threatened with actual perforation $(\mathrm{p}<0.0001)$, severe infection with threatened perforation $(\mathrm{p}=0.02)$ but not when comparing severe infection with actual perforation $(\mathrm{p}=0.9)$.

\section{Type of operation and techniques}

The majority of eCGs were done with a full thickness penetrating keratoplasty (1132 patients, 85.1\%) followed by deep anterior lamellar keratoplasty (6\%) and superficial lamellar keratoplasty (4\%), with other types of graft accounting for less than 5\% of eCGs. Interrupted suturing was the most frequently performed suturing technique $(82 \%)$, followed by continuous $(9 \%)$ and mixed $(7 \%)$. The size of most routine grafts was between $7.00 \mathrm{~mm}$ and $8.25 \mathrm{~mm} ; 78 \%$ compared with 43\% of eCG. Only $1 \%$ and $2 \%$ of routine grafts had a trephine diameter of less than $7.00 \mathrm{~mm}$ or greater than $8.75 \mathrm{~mm}$, respectively, compared with $10 \%$ and $23 \%$ of eCG. The majority of eCGs were oversized by $0.25 \mathrm{~mm}(19 \%)$ and $0.50 \mathrm{~mm}(45 \%)$, with $19 \%$ same-size grafts and $4 \%$ oversized by more than $0.50 \mathrm{~mm}$.

\section{Repeat eCGs}

A third of all emergency grafts were regrafts; 33\% (433/1330) compared with $18 \%(2063 / 11646)$ of routine grafts. The main indication for these was graft failure, recorded in 53\% (230/433) of redo-eCG compared with 74\% (1520/2063) of the routine regrafts. The other diagnostic categories for repeat eCG were infection (19\%), ulcerative keratitis (14\%), rejection (7\%) and endophthalmitis (1\%). Of the 84 patients who were regrafted due to infection, $52(62 \%)$ were for a bacterial infection. Most of the redo-eCGs had regrafts in the same eye while fewer eCG patients had previously received grafts in the other eye $(33 \%$ compared with $18 \%, \mathrm{p}<0.0001)$.

\section{Visual acuity}

The median best-corrected visual acuity (BCVA) improved from hand movements at the time of transplant to 6/24 (20/80) at 2 years. Most patients (81\%) showed an improvement in distance VA following eCG, 11\% had no change and only $8 \%$ of patients experienced deterioration in distance VA. Figure 2 shows a graph with lines of improvement in the Snellen chart for cases who had completed 1-year follow-up with records of preoperative and 1-year postoperative BCVA.

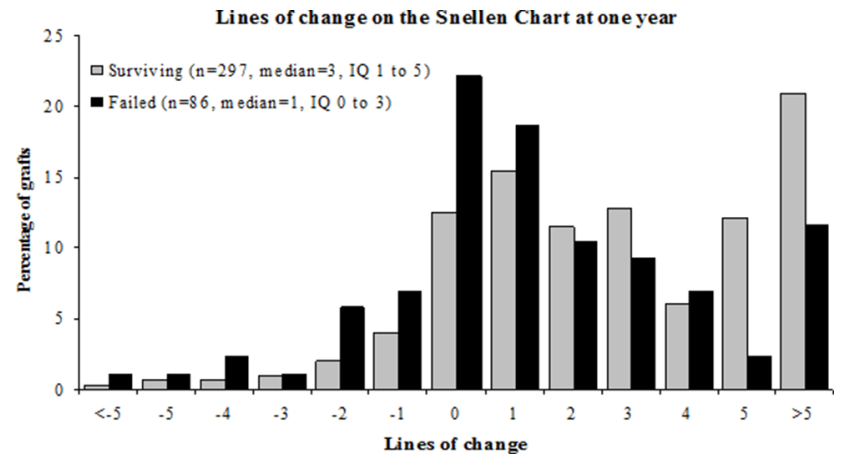

Figure 2 Lines of change on the vision at Snellen chart. Although uncorrected distance visual acuity was recorded for a large number of cases, only grafts with best-corrected visual acuity recorded in the UK Audit forms were included in this graph.
Table 2 Relative risk of graft failure at 5 years

\begin{tabular}{|c|c|c|c|c|}
\hline Factor & $\mathbf{n}$ & $\begin{array}{l}\text { Relative } \\
\text { risk }\end{array}$ & $95 \% \mathrm{Cl}$ & p Value \\
\hline \multicolumn{5}{|l|}{ Indication for graft $(p=0.01)$} \\
\hline Viral infection & 82 & 1.0 & - & \\
\hline Other infections & 195 & 2.2 & 1.3 to 3.6 & 0.003 \\
\hline Ulcerative keratitis & 195 & 1.8 & 1.1 to 3.1 & 0.03 \\
\hline Ectasias/dystrophies & 57 & 0.93 & 0.4 to 2.2 & 0.9 \\
\hline Other indications & 114 & 1.4 & 0.8 to 2.6 & 0.2 \\
\hline \multicolumn{5}{|l|}{ Preoperative acuity $(p=0.0002)$} \\
\hline Better than light perception & 466 & 1.0 & - & \\
\hline Light perception, NP & 144 & 1.8 & 1.3 to 2.4 & 0.0005 \\
\hline Not reported & 33 & 2.1 & 1.3 to 3.7 & 0.006 \\
\hline \multicolumn{5}{|l|}{ Graft size $(p=0.02)$} \\
\hline$<9.00 \mathrm{~mm}$ & 477 & 1.0 & - & \\
\hline$\geq 9.00 \mathrm{~mm}$ & 147 & 1.6 & 1.1 to 2.1 & 0.006 \\
\hline Not reported & 19 & 1.2 & 0.6 to 2.4 & 0.6 \\
\hline \multicolumn{5}{|l|}{ Preoperative conditions $(p=0.02)$} \\
\hline No & 312 & 1.0 & - & \\
\hline Yes & 178 & 1.5 & 1.1 to 2.1 & 0.02 \\
\hline Unknown & 153 & 1.5 & 1.1 to 2.1 & 0.02 \\
\hline \multicolumn{5}{|l|}{ Gender match $(p=0.05)$} \\
\hline Female donor/female recipient & 137 & 1.0 & - & \\
\hline Female donor/male recipient & 134 & 1.1 & 0.7 to 1.8 & 0.6 \\
\hline Male donor/female recipient & 192 & 1.5 & 0.99 to 2.3 & 0.05 \\
\hline Male donor/male recipient & 180 & 1.7 & 1.1 to 2.5 & 0.02 \\
\hline \multicolumn{5}{|l|}{ Grafted for visual reasons $(p=0.09)$} \\
\hline Yes & 328 & 1.0 & - & \\
\hline No & 246 & 1.3 & 0.99 to 1.8 & 0.06 \\
\hline Unknown & 69 & 1.5 & 0.95 to 2.4 & 0.08 \\
\hline
\end{tabular}

\section{Rejection, survival and risk of graft failure}

Rejection episodes occurred in 28 (4\%) eCGs, of which 24 $(86 \%)$ went onto fail. The overall graft survival of first eCG at 1,2 and 5 years was $78 \%, 66 \%$ and $47 \%$, respectively with $88 \%$ of the grafts surviving the first year being alive at year 2 . Table 2 shows the factors affecting graft survival for the first eCG.

Compared with grafts for viral infection, eCGs performed for non-infectious ulcerative keratitis were 1.8 times more likely to fail at 5 years $(p=0.03)$. Similarly, the prognosis for grafts with preoperative visual acuity of light perception (LP) or no light perception (NLP) was poorer than those better than LP; 1.8 times more likely to fail at 5 years $(p=0.0005)$. eCGs where the graft size was $9.00 \mathrm{~mm}$ or greater were 1.6 times more likely to fail at 5 years, compared with grafts less than $9.00 \mathrm{~mm}$ in diameter $(\mathrm{p}=0.006)$. Patients with preoperative conditions that may affect visual acuity were 1.5 times more likely to fail than patients with no reported preoperative conditions $(p=0.02)$. Gender match of male donor cornea to male recipient was an additional risk of graft failure; 1.7 times more likely to fail than female donor cornea to female recipients.

\section{DISCUSSION}

The first successful corneal transplant into a human eye ${ }^{26}$ was performed over 100 years ago and since then the technique has evolved and become the most widely practised form of clinical transplant worldwide. CG surgery can be performed both as a planned elective operation and as an emergency. Elective CG is usually straightforward and its primary goal is to improve vision 
in patients who suffer with a stable eye condition like keratoconus, Fuchs' corneal dystrophy, pseudophakic bullous keratopathy or a corneal scar. Although eCG is performed in patients with trauma, ulceration or a critical corneal thinning/perforation with the aim to restore the structural integrity of the globe with visual improvement, generally a secondary consideration. In patients with severe corneal infection, eCG surgery is also indicated to remove or decrease the microbial load present in the excised tissue.

Corneal allografts generally have a low rejection rate occurring in less than $10 \%$ of the patients who have not previously received a corneal transplant and who do not have underlying ocular inflammation. Corneal grafts can survive even though HLA typing and systemic immunosuppressive drugs are not employed for the majority of grafts. The success of corneal transplants is due to a combination of anatomical, physiological and immunological properties that prevent the induction and expression of potentially destructive immune responses to the transplanted tissue. ${ }^{27}$

In our study, we assessed the indications and outcomes, graft survival, rejection rates and final visual acuity of up to 1330 eCGs. This is the largest cohort of patients with eCG studied to date. Studies from other graft surgery are limited to fewer numbers. ${ }^{6-25}$

We found that the most frequent indication for eCG was infection. Subgroup analysis reveals bacterial, viral, acanthamoebal and fungal infections with an incidence of $20.8 \%, 11 \%, 2.7 \%$ and $2.1 \%$, respectively. Previous studies on CG and therapeutic penetrating keratoplasty have shown a broad range of frequencies for bacterial (1.77\%-40\%), ${ }^{28}$ viral $(2.19 \%-35 \%),{ }^{29}$ fungal $(0.19 \%-$ $48.1 \%)^{30}$ and acanthamoebal $(0.19 \%-13.9 \%)^{31}$ keratitis and a smaller number for descemetoceles, ${ }^{32}$ corneoscleral melting, ${ }^{33}$ trauma ${ }^{34}$ and repeat grafts. ${ }^{35}$ This variation may reflect a smaller patient number, too broad a definition/inclusion under 'other diagnosis' and the geographical and ethnic variability of these studies. The second most frequent indication in our study was sterile ulcerative keratitis (32.2\%), which was either idiopathic $(17.3 \%)$ or associated with rheumatoid disease (14.9\%). Repeat grafts (433) were mainly performed for graft failure (53.1\%), infection (19.4\%) and ulcerative keratitis (14.1\%).

Emergency graft survival rates were highly dependent on the diagnostic group under the indication for eCG surgery with ulcerative and bacterial keratitis, fairing worse than viral infection (figure 3). Graft survival was worse for grafts with preoperative visual acuity of LP or NPL, large graft size of $>9.00 \mathrm{~mm}$, associated preoperative conditions, previous rejection episodes and gender match of male donor cornea to male recipient was an additional risk (table 2). Emergency regrafts had a worst outcome with $65 \%$ of the grafts surviving the first year. Comparison with other studies with regards of survival rate of eCG is difficult, as most previous work focuses on one diagnostic category, typically with small sample numbers. Nonetheless, our data corroborate previous studies, showing that the presence of infection, inflammation, glaucoma and large diameter grafts are linked to poorer graft survival. ${ }^{6}$

Despite the poor prognosis of eCG, overall graft survival in these high-risk transplants was 78\% at the end of their first year compared with $90 \%$ of patients receiving an elective cornea graft operation, which compares favourably with other organ transplants where $85 \%$ of patients receiving a cadaveric kidney, $77 \%$ of patients receiving a heart and $65 \%$ of patients receiving a liver will have a functioning graft 1 year after the operation. ${ }^{3}$

Patients receiving their first eCG that had not failed were able to achieve visual acuity of $6 / 12(20 / 40)$ or better in $30 \%$ of the

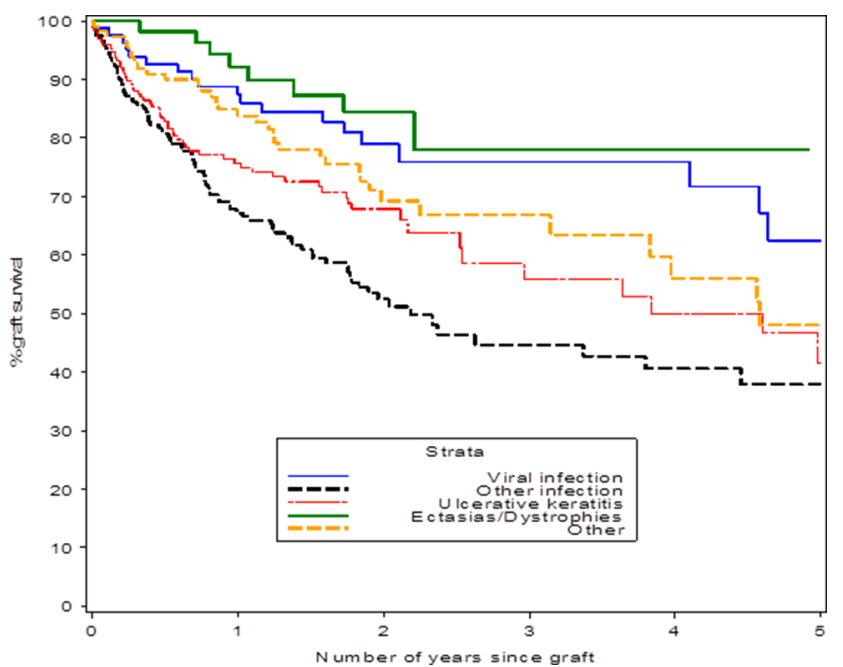

Figure 3 Survival of emergency corneal grafts according to indication. The percentage of graft survival for ectasias and dystrophies $(n=57)$ was $78 \%(95 \% \mathrm{Cl} 44$ to 76$)$, other $(n=114) 48 \%(95 \% \mathrm{Cl} 31$ to 66$)$, ulcerative keratitis ( $n=195) 41 \%(95 \% \mathrm{Cl} 26$ to 56$)$, other infection $(\mathrm{n}=195) 38 \%$ (95\% Cl 27 to 48) with $\mathrm{p}<0.0001$ (log-rank test).

eyes, $6 / 18(20 / 50)$ to $6 / 60(20 / 200)$ in $38.4 \%$ and only $30.6 \%$ had visual acuity of less than counting fingers at $1 \mathrm{~m}$. In this group, vision improved in $90 \%$ of the patients and in $60 \%$ improved by more than five Snellen lines with only 1\% of patients unable to recover any vision. Overall, following eCG the vision decreased in only 26 patients (8.7\%) with both surviving and failing grafts achieving a postoperative improvement in vision.

However in eCG the graft rejection rate is higher and depending on indication it can increase up to $32.1 \%$ in 4.4 years. ${ }^{36}$ In our study this was $4.2 \%$ in the first year. In our study, HLA matching was carried out in 823 (7.1\%) elective CG and 44 (3.3\%) eCG with just over $50 \%$ of them performed for regrafts. Previous studies have successfully argued that HLA matching does not appear to have a significant effect on corneal graft survival in elective CG patients. ${ }^{37}$ However, there is a strong consensus among clinicians that this may not be the case in eCG where there is a breakdown of corneal immune-privileged status. A vascularised corneal graft bed, along with a concurrent corneal infection and/or inflammation, promotes the induction of alloimmunity and jeopardises graft survival. Therefore, there may be a role for HLA matching in eCG surgery. The prolonged use of postoperative systemic/topical immune suppression and antiviral treatment regimens may be beneficial in eCG, however, they need to be evaluated with further studies.

Our study provides demographic, clinical and surgical factors that show the outcome of eCG surgery, and this information can be used to counsel corneal transplant patients about the long-term outcome of their surgery. This study reinforces the importance of eye banking and provision of emergency corneal graft material, confirming that eCG is a successful sight-saving operation.

Acknowledgements The authors gratefully acknowledge the voluntary contribution of records by over 500 ophthalmologists and other practitioners across the UK.

Contributors PH: contributions to the conception or design of the work; the acquisition, analysis or interpretation of data for the work; drafting the work or revising it critically for important intellectual content; final approval of the version to be published; agreement to be accountable for all aspects of the work in ensuring that questions related to the accuracy or integrity of any part of the work are appropriately investigated and resolved. AKT: interpretation of data for the work; 
drafting the work or revising it critically for important intellectual content; final approval of the version to be published. DK: interpretation of data for the work; drafting the work or revising it critically for important intellectual content; final approval of the version to be published. MJ: contributions to the conception or design of the work; the acquisition, analysis or interpretation of data for the work; final approval of the version to be published. DA: interpretation of data for the work; drafting the work or revising it critically for important intellectual content; final approval of the version to be published.

\section{Competing interests None declared.}

Patient consent Obtained.

Ethics approval UK Blood and Transplant approved this study.

Provenance and peer review Not commissioned; externally peer reviewed.

(c) Article author(s) (or their employer(s) unless otherwise stated in the text of the article) 2018. All rights reserved. No commercial use is permitted unless otherwise expressly granted.

\section{REFERENCES}

1 Naumann GO. The Bowman Lecture. Eye 1995;9 (Pt 4):395-421.

2 Johnson RWG, Dyer PA. 1998. Towards Standards for Organ and Tissue Transplantation in the United Kingdom. Richmond Surrey TW9 1GJ: British Transplantation Society.

3 NHS, Blood and Transplant. 2013. Organ Donation and Transplantation: NHS Blood and Transplant. Activity report. 75-83.

4 Thompson RW, Price MO, Bowers PJ, et al. Long-term graft survival after penetrating keratoplasty. Ophthalmology 2003;110:1396-402.

5 Vora GK, Haddadin R, Chodosh J. Management of corneal lacerations and perforations. Int Ophthalmol Clin 2013;53:1-10.

6 Killingsworth DW, Stern GA, Driebe WT, et al. Results of therapeutic penetrating keratoplasty. Ophthalmology 1993;100:534-41.

7 Williams KA, Muehlberg SM, Bartlett C. 2000. Australian Corneal Graft Register 1999, 2000 Report Adelaide.

8 Cunningham WJ, Brookes NH, Twohill HC, et al. Trends in the distribution of donor corneal tissue and indications for corneal transplantation: the New Zealand National Eye Bank Study 2000-2009. Clin Exp Ophthalmol 2012;40:141-7.

9 Vail A, Gore SM, Bradley BA, et al. Conclusions of the corneal transplant follow up study. Collaborating Surgeons. Br J Ophthalmol 1997;81:631-6.

10 Knox Cartwright NE, Tole DM, Georgoudis P, et al. Peripheral ulcerative keratitis and corneal melt: a 10-year single center review with historical comparison. Cornea 2014;33:27-31.

11 Keenan TD, Jones MN, Rushton S, et al. National Health Service Blood and Transplant Ocular Tissue Advisory Group and Contributing Ophthalmologists (Ocular Tissue Advisory Group Audit Study 8). Trends in the indications for corneal graft surgery in the United Kingdom: 1999 through 2009. Arch Ophthalmol 2012;130:621-8.

12 Muraine M, Sanchez C, Watt L, et al. Long-term results of penetrating keratoplasty. A 10-year-plus retrospective study. Graefes Arch Clin Exp Ophthalmol 2003;241:571-6.

13 Boujemaa C, Souissi K, Daghfous F, et al. [Urgent penetrating keratoplasty in perforated infectious corneal ulcers]. J Fr Ophtalmol 2005;28:267-72.

14 Fasolo A, Frigo AC, Böhm E, et al. CORTES Group. The CORTES study: corneal transplant indications and graft survival in an Italian cohort of patients. Cornea 2006;25:507-15.
15 Claesson M, Armitage WJ, Fagerholm P, et al. Visual outcome in corneal grafts: a preliminary analysis of the Swedish Corneal Transplant Register. Br J Ophthalmol 2002;86:174-80

16 Frucht-Pery J, Shtibel H, Solomon A, et al. Thirty years of penetrating keratoplasty in Israel. Cornea 1997;16:16???20-20.

17 Nurözler AB, Salvarli S, Budak K, et al. Results of therapeutic penetrating keratoplasty. Jpn J Ophthalmol 2004;48:368-71.

18 Al-Towerki AE, Gonnah e, Al-Rajhi A, et al. Changing indications for corneal transplantation at the King Khaled Eye Specialist Hospital (1983-2002). Cornea 2004;23:584-8.

19 Yang JW, Lin HC, Hsiao CH, et al. Therapeutic penetrating keratoplasty in severe infective keratitis using glycerol-preserved donor corneas. Cornea 2012;31:1103-6.

20 Li C, Zhao GQ, Che CY, et al. Effect of corneal graft diameter on therapeutic penetrating keratoplasty for fungal keratitis. Int J Ophthalmol 2012;5:698-703.

21 Sukhija J, Jain AK. Outcome of therapeutic penetrating keratoplasty in infectious keratitis. Ophthalmic Surg Lasers Imaging 2005;36:303-9.

22 Zhang AQ, Rubenstein D, Price AJ, et al. Evolving surgical techniques of and indications for corneal transplantation in Ontario: 2000-2012. Can J Ophthalmol 2013;48:153-9.

23 Módis L, Szalai E, Facskó A, et al. Corneal transplantation in Hungary (1946-2009). Clin Exp Ophthalmol 2011;39:520-5.

24 Zare M, Javadi MA, Einollahi B, et al. Changing indications and surgical techniques for corneal transplantation between 2004 and 2009 at a tertiary referral center. Middle East Afr J Ophthalmol 2012;19:323-9.

25 Ang M, Mehta JS, Sng CC, et al. Indications, outcomes, and risk factors for failure in tectonic keratoplasty. Ophthalmology 2012;119:1311-9.

26 Zirm EK. Eine erfolgreiche totale Keratoplastik (A successful total keratoplasty). 1906. Refract Corneal Surg 1989;5:258-61.

27 Niederkorn JY. Corneal immune privilege. Ocul Surf 2005;3:S158-60.

28 Chen WL, Wu CY, Hu FR, et al. Therapeutic penetrating keratoplasty for microbial keratitis in Taiwan from 1987 to 2001. Am J Ophthalmol 2004;137:736-43.

29 Maeno A, Naor J, Lee HM, et al. Three decades of corneal transplantation: indications and patient characteristics. Cornea 2000;19:7-11.

30 Panda A, Vajpayee RB, Kumar TS. Critical evaluation of therapeutic keratoplasty in cases of keratomycosis. Ann Ophthalmol 1991;23:373-6.

31 Awwad ST, Parmar DN, Heilman M, et al. Results of penetrating keratoplasty for visual rehabilitation after Acanthamoeba keratitis. Am J Ophthalmol 2005; 140:1080-4

32 Jonas JB, Rank RM, Budde WM. Tectonic sclerokeratoplasty and tectonic penetrating keratoplasty as treatment for perforated or predescemetal corneal ulcers. Am J Ophthalmol 2001;132:14-18.

33 Soong HK, Farjo AA, Katz D, et al. Lamellar corneal patch grafts in the management of corneal melting. Cornea 2000;19:126-34.

34 Doren GS, Cohen EJ, Brady SE, et al. Penetrating keratoplasty after ocular trauma. Am J Ophthalmol 1990;110:408-11.

35 Al-Mezaine H, Wagoner MD; King Khaled Eye Specialist Hospital Cornea Transplant Study Group. Repeat penetrating keratoplasty: indications, graft survival, and visual outcome. Br J Ophthalmol 2006;90:324-7.

36 Maier $P$, Böhringer D, Reinhard T. Clear graft survival and immune reactions following emergency keratoplasty. Graefes Arch Clin Exp Ophthalmol 2007;245:351-9.

37 Vail A, Gore SM, Bradley BA, et al. Conclusions of the corneal transplant follow up study. Collaborating Surgeons. Br J Ophthalmol 1997:81:631-6. 